\title{
A Memetic Algorithm for a Multi-Objective Obnoxious Waste Location-Routing Problem: A Case Study
}

\author{
Nasrin Asgari ${ }^{\text {a }}$, Mohsen Rajabi ${ }^{\text {b }}$, Masoumeh Jamshidi ${ }^{\text {c }}$, Maryam Khatami ${ }^{\text {d }}$, Reza Zanjirani Farahani ${ }^{e^{*}}$ \\ ${ }^{\text {a } U n i v e r s i t y ~ o f ~ R o e h a m p t o n, ~ R o e h a m p t o n ~ B u s i n e s s ~ S c h o o l, ~ L o n d o n, ~ T h e ~ U K ~}$ \\ ${ }^{\text {b }}$ Department of Industrial Management, Faculty of Management, Tehran University, Tehran, Iran \\ ${ }^{\mathbf{c}}$ Department of Industrial Engineering, Amirkabir University of Technology, Tehran, Iran \\ ${ }^{d}$ Department of Industrial and Systems Engineering, Texas A\&M University, College Station, TX, USA \\ ${ }^{\mathbf{e}}$ Department of Management, Kingston Business School, Kingston University, The UK
}

\begin{abstract}
This paper proposes a model for obnoxious waste location-routing problem (LRP) considering various types of wastes and several treatment technologies. The investigated distribution network includes three echelons of generation nodes, treatment and disposal facilities. A multi-objective LRP model is developed with three objective functions minimizing the treatment and disposal facility undesirability, different costs related to the problem, and eventually the risk associated with transportation of untreated materials. An effective memetic algorithm is developed in which a tabu search algorithm performs the local search. Comparison of exact and meta-heuristic methods run times confirms that the proposed method is effective. Eventually, the developed algorithm is tested on a real-life case study.
\end{abstract}

Keywords: obnoxious materials; location-routing problem (LRP); memetic algorithm; multi-criteria decision making (MCDM).

\section{Introduction}

Rapid industrial and technological development in recent years has increased the amount of generated wastes by different businesses. A significant portion of these wastes are obnoxious materials such as the wastes generated by dry cleaners, auto repair shops, exterminators, chemical manufacturers, and oil refineries. Obnoxious materials are defined as substances which threaten life and health of people and animals, and their environment. Explosive gases and liquids, flammable solids, toxic substances, corrosives, radioactively contaminated materials, nuclear wastes, and home wastes are examples of obnoxious and hazardous materials (HazMats). About 4 billion tons of HazMats are transported annually worldwide (Carotenuto et al., 2007). In 2007, 17.8\% of the total transported materials in the US were hazardous (Androutsopoulos and Zografos, 2010). Transporting these materials caused 88 serious incidents resulting in 15 deaths, 35 injuries, $\$ 37.75$ million property damage in 2003 in the USA only (Erkut, 2007).

\footnotetext{
* Corresponding. Fax: +44 0208417 7026; Tel: +44 0208517 5098; Email: zanjiranireza@ gmail.com
} 
Hazardous wastes are categorized into different types including universal, industrial, medical, construction, and electronic wastes like batteries and light bulbs, organic chemical production wastes, used needles, asbestos tiles, and computer CPUs, respectively. Before disposing these wastes, special treatment technologies are utilized for changing the physical, chemical, or biological characteristics of them in order to minimize their danger to people and environment. Each waste type has to be treated with a compatible treatment technology. For instance, if computer CPUs or CRT monitors are incinerated, they will cause health problems.

Due to the extensive risk of these materials, a variety of policies are devised for the purpose of storing, shipping, treating, and disposing of them. The policies are generally categorized into two groups of preventive and improving. Driver training, restricting transportation hours, special container specification, and special equipment are all regarded as preventive policies, while firefighting measures, rescuing and evacuating the residents are classified as improving ones. For example, in the UK, the safety assessment federation (SAFED) program provides driver training to encourage safe and fuel-efficient driving through a wide range of factors (McKinnon et al., 2010).

In addition, governments enforce regulations to ensure safe transportation of hazardous wastes. Prohibition of transporting hazardous wastes to town centers during restricted time of the day and obliging the supervisors to provide maximum safety are examples of government regulations. Consequently, companies may pass up the opportunity to use the routes with minimum costs, and choose the paths with higher costs but lower risks in order to adapt hazardous waste transportation laws. In other words, transportation companies try to keep costs as low as possible while governments insist on reducing transportation risk. Risk reduction policies, government regulations, and trade-off between risk and cost makes hazardous waste management problems more complicated. Hazardous waste management is dealing with collection, treatment, and disposal of waste materials in order to bring safety to the environment and health to human societies.

Hazardous waste location-routing problems (LRP) are developed in order to make the management of hazardous wastes efficient. In hazardous waste LRPs, location of the facilities like treatment and disposal centers, and shipping routes are determined based on different factors like facility opening and material transportation costs, risks to the people living in the facilities' proximity, safety of the paths, and governmental laws.

Because of the nature of these problems, majority of research articles in the area focus on minimizing cost and risk. Since several stakeholders with various objectives are involved in such decisions, a three-objective hazardous waste LRP with the goal of minimizing facility undesirability besides the cost and risk is investigated in this paper. We also take into account different types of wastes and consequently different treatment technologies to make the problem more realistic. Considering three objective functions results in increasing the time needed for solving the model 
drastically particularly in large-scale problems. In order to address this issue, the problem is decomposed into two sub-problems of location and routing with two objective functions in each. The outputs of location sub-problem are considered as inputs for the routing sub-problem. Decomposing the model also allows us to use a variety of cost and risk measures in each subproblem.

Hazardous waste LRP is NP-hard since it can be reduced to an uncapacitated facility location problem which is itself a NP-hard problem (Alumur and Kara, 2007). That is, computational effort for finding the exact solution of large-scale problems increases significantly. In this paper, a solution method based on a combination of memetic algorithm (MA) and tabu search (TS) is developed in order to obtain near optimum solution in reasonable time.

The remainder of this paper is structured as follows: In Section 2, related papers in the HazMat LRP literature are reviewed. Section 3 presents the problem description. The problem is formulated in Section 4. The solution method is proposed in Section 5. Test problems and computational results are presented in Section 6. In Section 7, the model is implemented on a case study in Singapore. Section 8 concludes the paper and provides future research suggestions.

\section{Literature review}

In Table 1, related papers in the literature are categorized based on characteristics of the investigated LRP. The last row of the table compares the contribution of this research against the literature. In this section, gaps in the literature are highlighted, and contribution of this research in filling the gaps is explained. 
Table 1. Classifications in the literature of hazardous waste LRP research papers.

\begin{tabular}{|c|c|c|c|c|c|c|c|c|c|c|c|c|c|c|c|c|c|c|c|c|}
\hline \multirow{2}{*}{ Reference } & \multicolumn{2}{|c|}{$\begin{array}{l}\text { Objective } \\
\text { function }\end{array}$} & \multicolumn{2}{|c|}{$\begin{array}{c}\text { Number of } \\
\text { periods }\end{array}$} & \multicolumn{2}{|c|}{$\begin{array}{l}\text { Vehicles } \\
\text { capacity }\end{array}$} & \multicolumn{2}{|c|}{$\begin{array}{c}\text { Vehicle } \\
\text { fleet }\end{array}$} & \multicolumn{2}{|c|}{$\begin{array}{l}\text { Facility } \\
\text { capacity }\end{array}$} & \multicolumn{2}{|c|}{$\begin{array}{l}\text { Nature of } \\
\text { demand }\end{array}$} & \multicolumn{3}{|c|}{$\begin{array}{c}\text { Hierarchical } \\
\text { level }\end{array}$} & \multicolumn{2}{|c|}{$\begin{array}{l}\text { Number of } \\
\text { waste types }\end{array}$} & \multicolumn{2}{|c|}{$\begin{array}{c}\text { Number of } \\
\text { technologies }\end{array}$} & \multirow{2}{*}{$\begin{array}{l}\text { Case } \\
\text { Study }\end{array}$} \\
\hline & $\begin{array}{l}\frac{0}{60} \\
\stackrel{=}{=}\end{array}$ & $\frac{\stackrel{0}{\cong}}{\stackrel{\Xi}{\Xi}}$ & $\begin{array}{l}\frac{0}{00} \\
\stackrel{\equiv}{5}\end{array}$ & $\frac{\stackrel{0}{:}}{\stackrel{\Xi}{\Xi}}$ & 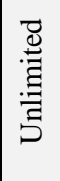 & 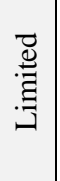 & $\begin{array}{l}\frac{0}{00} \\
\stackrel{: 0}{5}\end{array}$ & $\begin{array}{l}\stackrel{0}{\Xi} \\
\stackrel{\Xi}{\Xi} \\
\Sigma\end{array}$ & 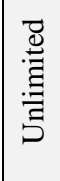 & 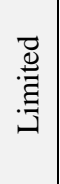 & 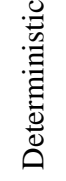 & 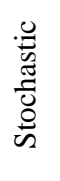 & $\begin{array}{l}\frac{n}{0} \\
0 \\
0 \\
0 \\
3 \\
1\end{array}$ & $\begin{array}{l}\frac{0}{0} \\
\stackrel{0}{0} \\
0 \\
0 \\
0 \\
0\end{array}$ & 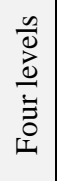 & $\begin{array}{l}\frac{0}{00} \\
\stackrel{0}{\leftrightarrows}\end{array}$ & $\frac{\stackrel{0}{\Xi}}{\stackrel{\Xi}{\Xi}}$ & $\begin{array}{l}\frac{0}{b 0} \\
\stackrel{\Xi}{5}\end{array}$ & $\frac{\stackrel{0}{\Xi}}{\stackrel{\Xi}{\Xi}}$ & \\
\hline $\begin{array}{l}\text { Zografos and } \\
\text { Samara (1989) }\end{array}$ & & $\checkmark$ & $\checkmark$ & & $\checkmark$ & & $\checkmark$ & & & $\checkmark$ & $\checkmark$ & & $\checkmark$ & & & $\checkmark$ & & $\checkmark$ & & \\
\hline List et al. (1991) & & $\checkmark$ & $\checkmark$ & & $\checkmark$ & & $\checkmark$ & & $\checkmark$ & & $\checkmark$ & & $\checkmark$ & & & & $\checkmark$ & & $\checkmark$ & $\checkmark$ \\
\hline $\begin{array}{l}\begin{array}{l}\text { Revelle et } a l . \\
(1991)\end{array} \\
\end{array}$ & & $\checkmark$ & $\checkmark$ & & $\checkmark$ & & $\checkmark$ & & $\checkmark$ & & $\checkmark$ & & $\checkmark$ & & & $\checkmark$ & & $\checkmark$ & & $\checkmark$ \\
\hline \begin{tabular}{|l|} 
Stowers and \\
Palekar (1993)
\end{tabular} & & $\checkmark$ & $\checkmark$ & & $\checkmark$ & & $\checkmark$ & & $\checkmark$ & & $\checkmark$ & & $\checkmark$ & & & $\checkmark$ & & $\checkmark$ & & \\
\hline $\begin{array}{l}\text { Jacobs and } \\
\text { Warmerdam } \\
\text { (1994) }\end{array}$ & & $\checkmark$ & & $\checkmark$ & $\checkmark$ & & $\checkmark$ & & & $\checkmark$ & $\checkmark$ & & $\checkmark$ & & & $\checkmark$ & & $\checkmark$ & & $\checkmark$ \\
\hline \begin{tabular}{|l|} 
Current and \\
Ratick (1995) \\
\end{tabular} & & $\checkmark$ & $\checkmark$ & & $\checkmark$ & & $\checkmark$ & & & $\checkmark$ & $\checkmark$ & & $\checkmark$ & & & $\checkmark$ & & $\checkmark$ & & \\
\hline \begin{tabular}{|l} 
Wyman and \\
Kuby (1995)
\end{tabular} & & $\checkmark$ & $\checkmark$ & & $\checkmark$ & & $\checkmark$ & & & $\checkmark$ & $\checkmark$ & & $\checkmark$ & & & $\checkmark$ & & & $\checkmark$ & $\checkmark$ \\
\hline $\begin{array}{l}\text { Giannikos } \\
(1998)\end{array}$ & & $\checkmark$ & $\checkmark$ & & $\checkmark$ & & $\checkmark$ & & & $\checkmark$ & $\checkmark$ & & $\checkmark$ & & & $\checkmark$ & & $\checkmark$ & & \\
\hline \begin{tabular}{|l} 
Nema and \\
Gupta (1999)
\end{tabular} & & $\checkmark$ & $\checkmark$ & & $\checkmark$ & & $\checkmark$ & & & $\checkmark$ & $\checkmark$ & & & $\checkmark$ & & & $\checkmark$ & & $\checkmark$ & \\
\hline \begin{tabular}{|l} 
Nema and \\
Gupta (2003)
\end{tabular} & & $\checkmark$ & $\checkmark$ & & $\checkmark$ & & $\checkmark$ & & & $\checkmark$ & $\checkmark$ & & & $\checkmark$ & & & $\checkmark$ & & $\checkmark$ & \\
\hline $\begin{array}{l}\text { Zhang et al. } \\
(2005)\end{array}$ & & $\checkmark$ & $\checkmark$ & & $\checkmark$ & & $\checkmark$ & & $\checkmark$ & & $\checkmark$ & & & $\checkmark$ & & $\checkmark$ & & $\checkmark$ & & \\
\hline \begin{tabular}{|l} 
Alumur and \\
Kara (2007)
\end{tabular} & & $\checkmark$ & $\checkmark$ & & $\checkmark$ & & $\checkmark$ & & & $\checkmark$ & $\checkmark$ & & & $\checkmark$ & & & $\checkmark$ & & $\checkmark$ & $\checkmark$ \\
\hline $\begin{array}{l}\text { Caballero et } a l \text {. } \\
(2007)\end{array}$ & & $\checkmark$ & $\checkmark$ & & & $\checkmark$ & $\checkmark$ & & & $\checkmark$ & $\checkmark$ & & $\checkmark$ & & & $\checkmark$ & & $\checkmark$ & & $\checkmark$ \\
\hline Xie et al. (2012) & & $\checkmark$ & $\checkmark$ & & $\checkmark$ & & $\checkmark$ & & & $\checkmark$ & $\checkmark$ & & & $\checkmark$ & & $\checkmark$ & & $\checkmark$ & & $\checkmark$ \\
\hline \begin{tabular}{|l|} 
Boyer et $a l$. \\
$(2013)$
\end{tabular} & & $\checkmark$ & $\checkmark$ & & $\checkmark$ & & $\checkmark$ & & & $\checkmark$ & $\checkmark$ & & & & $\checkmark$ & $\checkmark$ & & $\checkmark$ & & $\checkmark$ \\
\hline \begin{tabular}{|l} 
Samanlioglu \\
$(2013)$
\end{tabular} & & $\checkmark$ & $\checkmark$ & & $\checkmark$ & & $\checkmark$ & & & $\checkmark$ & $\checkmark$ & & & & $\checkmark$ & & $\checkmark$ & & $\checkmark$ & $\checkmark$ \\
\hline \begin{tabular}{|l|} 
Berglund and \\
Kwon (2014) \\
\end{tabular} & $\checkmark$ & & $\checkmark$ & & $\checkmark$ & & $\checkmark$ & & $\checkmark$ & & & $\checkmark$ & $\checkmark$ & & & $\checkmark$ & & $\checkmark$ & & $\checkmark$ \\
\hline \begin{tabular}{|c|}
$\begin{array}{c}\text { Our suggested } \\
\text { model }\end{array}$ \\
\end{tabular} & & $\checkmark$ & $\checkmark$ & & & $\checkmark$ & & $\checkmark$ & & $\checkmark$ & $\checkmark$ & & & $\checkmark$ & & & $\checkmark$ & & $\checkmark$ & $\checkmark$ \\
\hline
\end{tabular}

Majority of papers in the literature of hazardous waste LRP formulate problems as multiobjective mathematical models since different criteria impact locations of facilities and routing decisions. Most related research papers in the literature are similar in considering the risk and cost as objective functions (e.g. Alumur and Kara, 2007; Xie et al., 2012; Samanlioglu, 2013; Zhao and Verter, 2015). In order to minimize environment-related risks and total cost, Zhao and Verter (2015) present a bi-objective model for the LRP. They have applied a modified weighted goal programming approach. Samanlioglu (2013) minimizes total costs of transporting and processing hazardous wastes, transportation risk which threatens people living along the routes, and site risks which are caused by disposal and treatment facilities. Another important criterion which is taken into account in some papers is distributing the risk equitably among different population centers 
(e.g., Wyman and Kuby, 1995; Giannikos, 1998; Zhang et al., 2005). Zhang et al. (2005) develop a multi-objective mathematical model to minimize costs and potential risks, and to maximize risk equity. In this paper, besides costs and transportation risks, facility undesirability and vehicle utilization are minimized.

Hazardous waste managers try to manage different types of wastes which usually need special treatment and disposal facilities. Therefore, it is reasonable to differentiate among different waste types in modelling LRPs. In early research efforts in this area, it is assumed there is only one type of hazardous waste to simplify the problem. For the first time, List et al. (1991) investigated different types of wastes, and consequently, different treatment technologies. Similarly, in this paper, simplifying assumption of single waste and technology in hazardous waste LRP is relaxed.

Different types of hazardous wastes have to comply with vehicles used to ship them. As instance, solid wastes are transported in different vehicles than those used for liquid wastes. In addition, vehicles have different capacities which impact transportation costs. Hence, in real-world hazardous waste LRPs, choosing the appropriate vehicle to ship the wastes is one of the concerns of managers which have not been investigated in the literature so far. In this paper, different types of vehicles with different capacities are considered in order to model a more realistic problem.

Demand of generation nodes and capacity of the treatment and disposal facilities are two main factors based on which decisions on the number of required facilities are made. In some research papers, like Zhang et al. (2005) and Berglund and Kwon (2014), it is assumed that the capacity of waste processing facilities is unlimited which is a simplifying assumption. It is appropriate to consider capacitated facilities in order to make the model applicable for real-world problems. In this paper, capacity of treatment facilities and disposal centers is limited.

In some cases, hazardous wastes can be recycled in generation nodes and/or treatment facilities. This reduces the raw material and energy consumption, and amount of wastes that need to be disposed. In treatment facilities, besides recycling the wastes, they are treated in order to reduce their negative effects on people and environment. After treatment, the wastes are no longer hazardous. Therefore, transporting the treated wastes from treatment facilities to disposal facilities does not threaten the population along the routes anymore. In order to consider the difference between managing wastes before and after treatment, it is appropriate to take into account three different levels of generation nodes, treatment facilities, and disposal facilities; which is how the problem is defined in this paper. Majority of the research papers in the literature consider two levels of generation nodes and treatment/disposal facilities (e.g. Giannikos, 1998; Caballero et al., 2007; and Berglund and Kwon, 2014).

In some research papers like Alumur and Kara (2007), Xie et al. (2012), Samanlioglu (2013), and Li et al. (2015), the applicability of the model is demonstrated by solving a real case problem. 
Alumur and Kara (2007) implement their model in the Central Anatolian region of Turkey. Xie et al. (2012) justify their model by using it to solve the problem in 20 southern states of United States. Samanlioglu (2013) apply the model to solve the hazardous waste LRP in Marmara region of Turkey. Li et al. (2015) have chosen an industrial intensive district in Hebei Province in China as an empirical object to study their model result. We examined our model in a case study of hazardous waste management in Singapore.

Considering the problem in single period context and ignoring the uncertainty of demand in hazardous waste LRPs is a gap in the literature. Only Jacobs and Warmerdam (1994) investigate the problem in multi-period context, and Berglund and Kwon (2014) is the only research paper that takes into account the uncertainty of demand. This gap would be addressed in future research.

\section{Problem Description}

In an attempt to reduce energy and raw material consumption, a part of hazardous wastes are recycled in generation nodes. The remainder is transported to treatment centers on different types of vehicles with different capacities. Using treatment technologies, a part of wastes are recycled and remainders are treated. Harmless residue of wastes is transported to disposal facilities. A schematic presentation of the process is depicted in Figure 1.

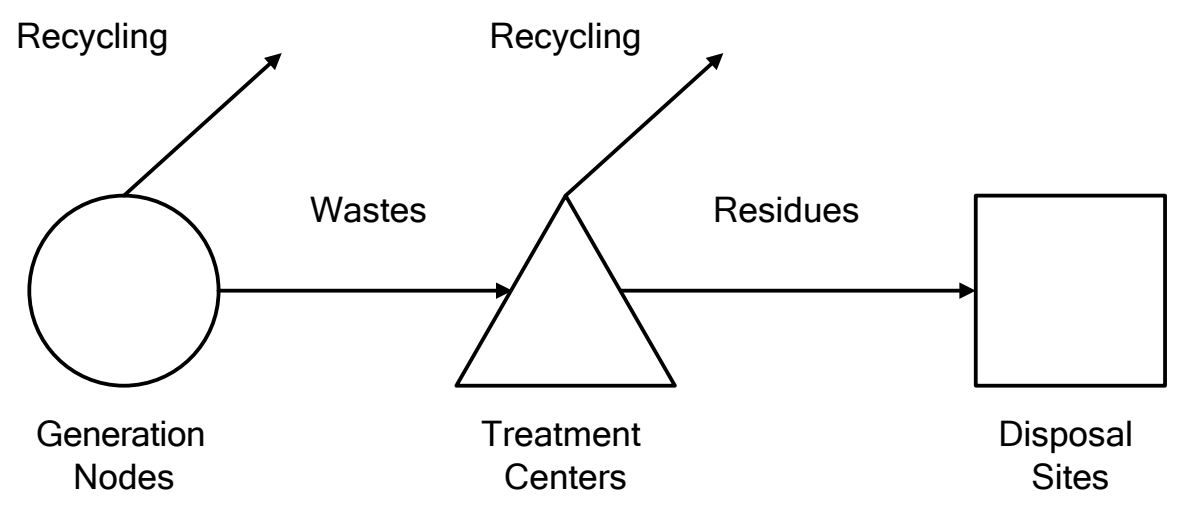

Figure 1. A schematic view of the network.

In order to have a better understanding of the problem, the stages and the routes in which vehicles travel are shown in Figure 2 which is called a 3/R/T layer diagram. " 3 " is the number of layers; " $R$ " means return and " $T$ " means tour. The lines show the routes of vehicles. Difference in types of lines reflects different types of wastes transported by their consistent vehicles. The figure demonstrates that a specialized vehicle travels through generation nodes 1 to 3 and transports no more than one particular type of waste to the treatment center. Another vehicle does the same for generation nodes 4 and 5. The wastes are then processed and the remaining materials, which are not by any means valuable, are transported to disposal sites. Each of the disposal sites 1 to 3 is adapted 
to bury residue of all types of hazardous wastes. As the result, vehicles transport different types of worthless remaining materials to disposal sites.

It is noticeable that vehicles assigned to a specific type of waste are parked in the treatment center which is equipped with technology of treating that type of waste. Hence, vehicles start their travel from treatment centers and return to the same place.

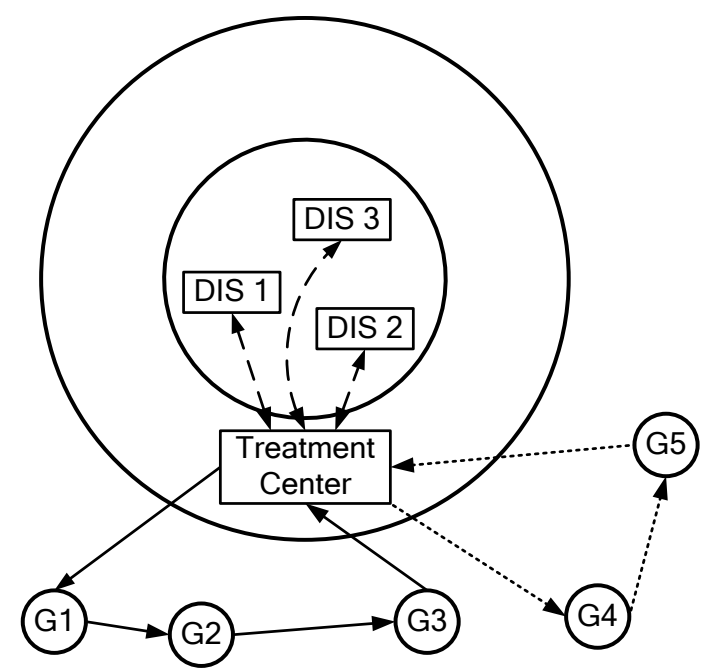

Figure 2. The 3/R/T layer diagram of the problem.

This study aims to introduce a model and a solution method for hazardous waste facility location and routing problem in order to manage the wastes in an efficient way with low risks. In this paper, the location-routing problem is formulated as a three-objective mathematical model. The model is broken down into two different parts: first one includes two objective functions of evenly distributing the facility undesirability and minimizing facility location costs; the second one aims to minimize transportation costs and risks. The reason of decomposing the problem into two parts is that since establishing obnoxious facilities often raises governmental and non-governmental organizations' resistance, related decisions are so risky, and it is probable to loss a huge amount of money due to inaccurate decision making. Therefore, undesirability of facilities and relevant costs should be studied and modeled independently from other decisions in LRP like routing and its costs.

Regarding location decisions, this paper attempts to select facility sites from specific potential locations as they cannot be established in all places due to governmental and environmental regulations. The capacities of treatment and disposal facilities are considered to be limited.

As different types of wastes are studied, waste-vehicle compatibility constraints are considered to ensure that wastes are transported using consistent vehicles. In addition, as different treatment technologies are needed to process different types of wastes, waste-technology compatibility constraints are taken into account to guarantee that wastes are in accordance with related treatment technologies. 
The opportunity to select among different types of vehicles with different capacities helps to transport the wastes between nodes more efficiently. Since vehicles are capacitated, the problem is of CVRP (Capacitated Vehicle Routing Problem) type. There is no partial delivery in the problem, which means demand for any product in any point is supplied by only one vehicle. It is assumed that waste transportation cost is independent of the waste type. Therefore, the transportation cost depends on the quantity of transported wastes and the tour length traveled. The problem data are assumed to be constant in a long period of time which makes the problem of static type. Demand in generation nodes is assumed to be deterministic.

\section{Problem Formulation}

In this section we formulate the problem as an optimization model that can provide a basis for the solution technique. First, we introduce notations used in the model and then present a closed-form formulation.

\subsection{Notations}

Main notations of the model are $\boldsymbol{m} / \boldsymbol{o} / \boldsymbol{w}$, where $\boldsymbol{m}$ is number of disposal sites, $\boldsymbol{o}$ indicates number of technology types, and $\boldsymbol{w}$ is the number of waste types. The notations used in the model are introduced as follows:

\section{Sets}

GEN : Set of generation nodes

$T R$ : Set of potential locations for treatment centers

$D I S:$ Set of potential locations for disposal centers

$Q:$ Set of treatment technologies, indexed by $q$

$W:$ Set of hazardous waste types, indexed by $w$

$V:$ Set of vehicle types, indexed by $v$

\section{Decision variables}

$n_{q i}$ : A binary variable equal to 1 if treatment technology $q$ is found at potential location $i ; 0$ otherwise

$u_{i}$ : A binary variable equal to 1 if a disposal center is established at potential location $i$; otherwise.

$y_{v}$ : A binary variable equal to 1 if vehicle $v$ is used; 0, otherwise.

$t_{w q}$ : A binary variable equal to 1 if waste $w$ is assigned to treatment technology $q$; 0, otherwise.

$m_{w v}$ : A binary variable equal to 1 if waste $w$ is shipped using vehicle $v$; 0 , otherwise. 
$x_{i j v}$ : A binary variable equal to 1 if vehicle $v$ is used to transport wastes through link $(i, j)$

$z_{i}$ : Quantity of wastes disposed at disposal center $i$

\section{Parameters}

$\Psi$ : Untreated waste vehicle leasing or purchasing cost in a certain period of time

$\alpha_{w i}$ : Recycling percentage of hazardous waste of type $w$ in generation node $i$

$\beta_{w}$ : Recycling percentage of hazardous waste of type $w$ in the corresponding treatment center

$\lambda_{q}$ : Undesirability ratio of disposal centers to treatment center equipped with treatment technology

$q$.

$\eta$ : Treated waste vehicle leasing or purchasing cost in a certain period of time

$c_{i j}$ : Transportation cost between nodes $i$ and $j$ which is independent of quantity

$d_{i j}$ : Distance between node $i$ and $j$

$p_{w i}$ : Quantity of hazardous waste $w$ produced in generation node $i$

$f_{q i}$ : Fixed cost of establishing treatment technology $q$ at potential location $i$

$g_{i}$ : Fixed opening cost of a disposal center at potential location $i$

$k_{v}$ : Capacity of vehicle $v$ for hazardous wastes before treatment

$l$ : Capacity of each vehicle for treated wastes

$a_{q i}$ : Capacity of treatment technology $q$ in potential location $i$

$o_{i}$ : Capacity of disposal center $i$

$e_{i}$ : Number of people living in node $i$

$\gamma, \theta$ : Parameters determined by decision maker

$r_{i j w}$ : Risk of transporting one unit of hazardous waste $w$ on link $(i, j)$

$b_{i j}$ : Full truckload cost for transporting treated wastes through shortest path from treatment center $i$ to disposal center $j$

$h(S)$ : Minimum number of vehicles needed to serve set $S, S \subseteq G E N$

According to notations explained above, the problem can be formulated as follows:

$\operatorname{Min} Z_{1}=\sum_{i \in G E N} \sum_{j \in T R} \sum_{q \in Q} \frac{\left(e_{i} a_{q j} n_{q j}\right)^{\gamma}}{d_{i j}{ }^{\theta}}+\sum_{q \in Q} \lambda_{q}\left(\sum_{i \in G E N} \sum_{j \in D I S} \frac{\left(e_{i} o_{j} u_{j}\right)^{\gamma}}{\left(d_{i j}\right)^{\theta}}\right)$

$\operatorname{Min} Z_{2}=\sum_{q \in Q} \sum_{i \in T R} f_{q i} n_{q i}+\sum_{i \in D I S} g_{i} u_{i}+\sum_{i \in G E N} \sum_{j \in T R} \sum_{v} c_{i j} x_{i j v}+\Psi \sum_{v} y_{v}$

$+\sum_{i \in T R} \sum_{j \in D I S} \sum_{q \in Q} b_{i j} n_{q i}\left\lceil\frac{Z_{j} u_{j}}{l}+1\right\rceil+\eta \sum_{i \in D I S} u_{i}$

$\operatorname{Min} Z_{3}=\sum_{i \in G E N} \sum_{j \in T R} \sum_{v} \sum_{w} x_{i j v} r_{i j w} m_{w v}$ 


$$
\begin{aligned}
& \sum_{i \in T R} n_{q i}=1 \\
& \sum_{q \in Q} t_{w q}=1 \quad \forall w \in W \\
& \sum_{j \in T R} a_{q j} n_{q j} \geq \sum_{w \in W} \sum_{i \in G E N}\left(1-\alpha_{w i}\right) p_{w i} t_{w q} \quad \forall q \in Q \\
& \sum_{j \in D I S} o_{j} u_{j} \geq \sum_{w}\left(\left(1-\beta_{w}\right) \sum_{i \in G E N}\left(1-\alpha_{w i}\right) p_{w i}\right) \\
& \sum_{w} m_{w v}=1 \\
& \sum_{i \in G E N} x_{j i v}=m_{w v} t_{w q} v_{q j} \quad \forall j \in T R, v \in V, q \in Q, w \in W \\
& \sum_{i \in G E N} x_{i j v}=m_{w v} t_{w q} v_{q j} \quad \forall j \in T R, v \in V, q \in Q, w \in W \\
& \sum_{i \in G E N \cup T R} \sum_{v} x_{i j v} m_{w v}=1 \quad \forall i \neq j, j \in G E N, w \in W \\
& \sum_{j \in G E N \cup T R} \sum_{v} x_{i j v} m_{w v}=1 \quad \forall i \neq j, i \in G E N, w \in W \\
& \sum_{j \in G E N \cup T R} x_{i j v}=\sum_{k \in G E N \cup T R} x_{j k v} \quad \forall j \in G E N, v \in V \\
& y_{v} \geq x_{i j v} \quad \forall v,(i, j) \in\{(G E N, G E N),(G E N, T R),(T R, G E N)\} \\
& m_{w v}\left(\sum_{i \in G E N} p_{w i} \sum_{j \in G E N \cup T R} x_{i j v}\right) \leq k_{v} \quad \forall v, w \\
& \sum_{j \in D I S} z_{j} u_{j}=\sum_{w}\left(\left(1-\beta_{w}\right) \sum_{i \in G E N}\left(1-\alpha_{w i}\right) p_{w i}\right) \\
& \sum_{i} \sum_{j} \sum_{v} x_{i j v} \geq t(S) \quad \forall S \subseteq G E N, S \neq \varnothing \\
& z_{j} \leq M u_{j} \\
& \forall j \in D I S \\
& z_{i} \geq 0 \\
& \forall i \in D I S \\
& n_{q i}, u_{i}, y_{v}, t_{w q}, m_{w v}, x_{i j v} \in\{0,1\} \\
& \forall i, j, q, w, v
\end{aligned}
$$

Objective function (1) minimizes the sum of treatment and disposal centers' undesirability throughout the region. Undesirability of a facility to a specific node is an increasing function of the population living in the node and the facility size, and a decreasing function of the distance between the node and the facility. The value of $\gamma$ and $\theta$ should be determined by decision makers based on 
the characteristics of their problem. It is clear that if $\gamma$ increases the undesirability grows, and increasing $\theta$ means reducing undesirability. For example, regarding the population, if the number of children and old people in a population is a big number, the decision maker should assign a greater value to parameter $\gamma . \theta$ should be determined according to the characteristics of the hazardous material. For example the influence radius of a material is different than that of the others. The decision maker should choose a higher value for $\theta$ if the influence radius of the material is small. Undesirability of a disposal centre could be considered more or less than that of a treatment centre. After treating the materials in treatment centers, the residues are normally less hazardous compared to the materials before treatment. $\lambda_{q}$ determines the fraction of risk remained after treatment. Hence, the value of $\lambda_{q}$ depends on the material and the treatment technology. The terms of objective function (2) correspond to location costs of treatment and disposal facilities, transportation costs of untreated wastes, cost of leasing the vehicles used for transporting untreated waste, transportation costs of residue wastes after treatments, and cost of leasing the vehicles used for transporting residue wastes, respectively. Objective function (3) minimizes the risk of transporting untreated wastes. It should be noted that residue wastes after treatment do not impose any risk on people and environment.

Constraints (4) ensure that each type of treatment technology is available in only one treatment center. According to constraints (5), each waste type is consistent with only one treatment technology. Constraints (6) state that total capacity of settled treatment centers is greater than the demand of generation nodes after subtracting the amount of recycled wastes. Constraints (7), similarly, represent the capacity constraints for disposal facilities. Constraints (8) enforce that each waste type is transported using a specific vehicle type. As it is mentioned in Section 3, vehicles' parking lot is located in treatment centers. Constraints (9) show that the vehicle assigned to a specific waste type starts its route from the treatment center which is equipped with technology for treating that type of waste. Constraints (10) enforce that the end point of a vehicle's route is the related treatment center. Constraints (11) and (12) guarantee that only one corresponding vehicle to each waste type enters and leaves a generation node. Constraints (13) stipulate that each vehicle which enters a generation node leaves it. According to constraints (14), variable $Y_{v}$ is 1 if vehicle $v$ is used on at least one link. Constraints (15) enforce capacity limitations for vehicles. Constraint (16) guarantees that total amount of residue wastes after treatment are disposed in disposal centers. Constraints (17) are sub-tour elimination constraints associated with the problem called Capacity Cut Constraints (CCC). Constraints (18) ensure that residue wastes are disposed in a disposal centre only if it is established. Constraints (19) and (20) identify types of the variables. 


\section{Solution Method}

\subsection{Decomposing the Model}

As it is shown in the previous section, the model contains 3 objective functions. To solve the model, we divide it into two bi-objective models using MODM method. The solution technique is thus hierarchical including one location problem and one routing problem. The results of solving the first model are considered as parameters in second one. In doing so, the location and routing problems can be solved and modified separately. Two bi-objective models are as follows:

$$
\begin{aligned}
& \operatorname{Min} Z_{1}=\sum_{i \in G E N} \sum_{j \in T R} \sum_{q \in Q} \frac{\left(e_{i} a_{q j} n_{q j}\right)^{\gamma}}{d_{i j}{ }^{\theta}}+\sum_{q \in Q} \lambda_{q}\left(\sum_{i \in G E N} \sum_{j \in D I S} \frac{\left(e_{i} o_{j} u_{j}\right)^{\gamma}}{\left(d_{i j}\right)^{\theta}}\right) \\
& \operatorname{Min} Z_{2}=\sum_{q \in Q} \sum_{i \in T R} f_{q i} n_{q i}+\sum_{i \in D I S} g_{i} u_{i}
\end{aligned}
$$

Subject to:

Constraints (4)-(7)

$n_{q i}, u_{i}, t_{w q} \in\{0,1\}$

$$
\forall i, q, w
$$

Objective function (21) is the same as objective function (1). Objective function (22) minimizes location costs of treatment and disposal facilities. By solving this model, decisions regarding the locations of treatment and disposal facilities and assigning the technologies to established treatment centers, and wastes to technologies are made. The variables of the first model, $n_{q i}$ and $u_{i}$, are considered as parameters in the second model. They are represented by $n_{q i}^{\prime}$ and $u_{i}^{\prime}$ in the following model:

$$
\begin{aligned}
\operatorname{Min} Z_{3}=\sum_{i \in G E N} \sum_{j \in T R} \sum_{v} c_{i j} x_{i j v}+\Psi \sum_{v} y_{v}+\sum_{i \in T R} \sum_{j \in D I S} \sum_{q \in Q} b_{i j} n_{q i}^{\prime}\left\lceil\frac{z_{j} u_{j}^{\prime}}{l}+1\right\rceil \\
+\eta \sum_{i \in D I S} u_{i}^{\prime}
\end{aligned}
$$

$\operatorname{Min} Z_{4}=\sum_{i \in G E N} \sum_{j \in T R} \sum_{v} \sum_{w} x_{i j v} r_{i j w} m_{w v}$

Subject to

Constraints (8)-(19)

$y_{v}, m_{w v}, x_{i j v} \in\{0,1\}$

$$
\forall i, j, w, v
$$

Objective function (24) minimizes transportation costs, and vehicles' leasing or purchasing costs. Objective function (25) is the same as objective function (3). Results of this model determine routing and vehicle utilization decisions, and the amount of wastes disposed in each disposal center. 


\subsection{Solution Technique}

It is a common practice in the literature to use Sequential Methods, Iterative Methods, and Nested Methods to attack LRPs (Tuzun and Burke, 1999). Min et al. (1998) and Balakrishnan et al. (1987) believe that sequential methods are preferred for problems with considerable fixed cost of facilities and small number of vehicles from computational perspective.

Since the LRP is NP-hard (Alumur and Kara, 2007), using heuristic methods to solve the largescale problems is more efficient in terms of computational efforts. As it is shown in Table 2, we categorize 78 research papers in the scope of location-routing into 6 groups based on their solution methods.

Table 2. Classification of solution methods.

\begin{tabular}{|c|c|c|c|c|c|}
\hline Exact & Heuristics & Meta-heuristics & $\begin{array}{l}\text { Combination of } \\
\text { meta-heuristics }\end{array}$ & $\begin{array}{l}\text { Combination of } \\
\text { heuristics and } \\
\text { meta-heuristics }\end{array}$ & $\begin{array}{c}\text { Combination of } \\
\text { exact and } \\
\text { heuristics }\end{array}$ \\
\hline $\begin{array}{c}\text { Zografos and Samara } \\
\text { (1989) }\end{array}$ & $\begin{array}{c}\text { Nagy and Salhi } \\
(1996)\end{array}$ & $\begin{array}{c}\text { Tuzun and Burke } \\
\text { (1999) }\end{array}$ & $\begin{array}{c}\text { Melechovskys et } a l . \\
(2005)\end{array}$ & Wu et al. (2002) & Prodhon (2007) \\
\hline List et al. (1991) & $\begin{array}{c}\text { Murty and Djang } \\
\text { (1998) }\end{array}$ & Lin et $a l .(2002)$ & Liu and Lin (2005) & $\begin{array}{c}\text { Ozyurt and Aksen } \\
(2005)\end{array}$ & $\begin{array}{c}\text { Androutsopoulos } \\
\text { and Zografos (2012) }\end{array}$ \\
\hline Revelle et al. (1991) & Chan et al. (2001) & Lee et $a l .(2003)$ & $\begin{array}{c}\text { Bouhafs et } a l \text {. } \\
\text { (2006) }\end{array}$ & Prins et al. (2007) & $\begin{array}{c}\text { Bronfman et al. } \\
(2015)\end{array}$ \\
\hline $\begin{array}{c}\text { Stowers and Palekar } \\
\text { (1993) }\end{array}$ & Liu and Lee (2003) & Sambola et al. (2005) & $\begin{array}{c}\text { Caballero et } a l \text {. } \\
\text { (2007) }\end{array}$ & Prodhon (2007) & Li et $a l .(2015)$ \\
\hline $\begin{array}{c}\text { Jacobs and } \\
\text { Warmerdam (1994) }\end{array}$ & $\begin{array}{c}\text { Cappanera et } a l \text {. } \\
(2003)\end{array}$ & Prins (2006) & $\begin{array}{c}\text { Lin and Kwok } \\
\text { (2006) }\end{array}$ & Klibi (2008) & \\
\hline \begin{tabular}{|c|} 
Current and Ratick \\
(1995)
\end{tabular} & $\begin{array}{c}\text { Wasner and Zapfel } \\
\text { (2004) }\end{array}$ & $\begin{array}{l}\text { Prodhon and Prins } \\
(2008)\end{array}$ & $\begin{array}{c}\text { Bouhafs et } a l . \\
(2008)\end{array}$ & $\begin{array}{c}\text { Duhamel et } a l \text {. } \\
\text { (2010) }\end{array}$ & \\
\hline $\begin{array}{c}\text { Wyman and Kuby } \\
(1995)\end{array}$ & $\begin{array}{c}\text { Chan and Baker } \\
(2005)\end{array}$ & Marinakis (2008) & $\begin{array}{c}\text { Doerner et } a l . \\
(2007)\end{array}$ & Moccia et al. (2012) & \\
\hline Giannikos (1998) & Zhang et $a l$. (2005) & $\begin{array}{c}\text { Schwardt and Fischer } \\
(2008)\end{array}$ & Dalfard et $a l .(2013)$ & & \\
\hline $\begin{array}{c}\text { Nema and Gupta } \\
\text { (1999) }\end{array}$ & Barreto et al. (2007) & $\begin{array}{c}\text { Schittekat and } \\
\text { Sörensen (2009) }\end{array}$ & & & \\
\hline $\begin{array}{c}\text { Nema and Gupta } \\
\text { (2003) }\end{array}$ & Sambola et al. (2007) & Yu et $a l .(2010)$ & & & \\
\hline $\begin{array}{l}\text { Ambrosino and } \\
\text { Scutella (2005) }\end{array}$ & $\begin{array}{c}\text { Salhi and Nagy } \\
(2007)\end{array}$ & Derigs et al. (2010) & & & \\
\hline $\begin{array}{l}\text { alumur and Kara } \\
\text { (2007) }\end{array}$ & $\begin{array}{c}\text { Androutsopoulos and } \\
\text { Zografos (2010) }\end{array}$ & $\begin{array}{c}\text { Pradhananga et } a l . \\
(2010)\end{array}$ & & & \\
\hline Aksen et $a l .(2008)$ & Mendoza et al. (2011) & $\begin{array}{l}\text { Nguyen et } a l . \\
(2012 \mathrm{a})\end{array}$ & & & \\
\hline Contardo (2007) & $\begin{array}{c}\text { Karaoglan et } a l . \\
\text { (2012) }\end{array}$ & $\begin{array}{l}\text { Nguyen et } a l . \\
(2012 b)\end{array}$ & & & \\
\hline Lopes (2008) & Willmer et al. (2013) & Derbel et al. (2012) & & & \\
\hline Akca (2008) & & $\begin{array}{c}\text { Ting and Chen } \\
\text { (2013) }\end{array}$ & & & \\
\hline Akca et al. (2009) & & Escobar et al. (2013) & & & \\
\hline \begin{tabular}{|c|} 
Rieck and \\
Zimmermann (2010) \\
\end{tabular} & & $\begin{array}{c}\text { Berglund and Kwon } \\
\text { (2014) }\end{array}$ & & & \\
\hline Baldacci et $a l$. (2011) & & $\begin{array}{c}\text { Assadipour et } a l \text {. } \\
(2015)\end{array}$ & & & \\
\hline $\begin{array}{c}\text { Belenguer et } a l . \\
(2011)\end{array}$ & & & & & \\
\hline Li and Leung (2011) & & & & & \\
\hline Xie et al. (2012) & & & & & \\
\hline Boyer et al. (2013) & & & & & \\
\hline Samanlioglu (2013) & & & & & \\
\hline \begin{tabular}{|c}
$\begin{array}{c}\text { Berglund and Kwon } \\
(2014)\end{array}$ \\
\end{tabular} & & & & & \\
\hline
\end{tabular}


Most research papers, that solve the model to optimality, like List et al. (1991), Stowers and Palekar (1993), Current and Ratick (1995), and Wyman and Kuby (1995) exploit optimization software like GAMS and LINDO; and CPLEX as the solver. However, it is not efficient to use optimization software for solving real-life large scale problems. In order to tackle this issue, metaheuristic methods like Tabu search, simulated annealing, ant colony, particle swarm, genetic algorithm, memetic algorithm, variable neighborhood search, and neural network are used to solve location-routing models.

The existing studies suggest that tabu search (TS) algorithm may be an appropriate method to solve the problem. Since TS is an improving algorithm, and the main factor affecting the optimal solution while using improving algorithms is the initial solution, genetic algorithm (GA) can be applied in order to generate initial solution to be fed to TS.

While classical genetic algorithm is often claimed to be deficient in terms of sufficient search intensification, memetic algorithm (MA) takes advantage of capability of efficient heuristics by combining domain knowledge and population-based search approaches like GA (Pishvaee et al., 2009, and Shen et al., 2015). MA has been widely used in optimization problems such as distribution problems (Boudia and Prins, 2009), timing problem (Moghaddam et al., 2009), and etc. As the result, the method used here will be an MA in which TS algorithm does the local search. We generate the initial solution using GA, and then apply TS to improve the solution. TS uses the current best solution as an initial solution to be improved using curve-fitting with respect to population property of a set of generated solutions.

\subsection{Chromosome Representation}

Location Model: If $N$ is the number of potential locations for disposal facilities and $K$ is the number of treatment technologies, the chromosome length is $N+K$. In Figure 3, $T$ indicates the location of corresponding treatment technology $Q$.

\begin{tabular}{|c|c|c|c|c|c|c|c|}
\hline 1 & 2 & 3 & $\ldots$ & $N-1$ & $N$ & $Q_{1}$ & $Q_{k}$ \\
\hline 0 & 1 & 0 & $\ldots$ & 1 & 0 & T(a) & $T(f)$ \\
\hline
\end{tabular}

Figure 3. Location chromosome representations.

Routing Model: An arbitrary solution for routing model is shown in Figure 4. It is considered that the number of waste types is 2 and the number of customers is 12. Each waste type is collected using the corresponding vehicle through 3 trips. 


\begin{tabular}{|c|c|c|c|c|c|c|c|c|c|}
\hline & \multicolumn{4}{|c|}{ "Waste Type 1} & \multicolumn{5}{|c|}{ Waste Type 2} \\
\hline 2 & 1 & 6 & 5 & & 6 & 3 & 7 & & \\
\hline 7 & 4 & & & & 8 & 5 & 1 & 2 & \\
\hline 3 & 8 & 9 & 11 & 12 & $\overline{11}$ & 9 & 12 & 10 & 4 \\
\hline
\end{tabular}

Figure 4. An arbitrary routing solution.

Figure 5 shows the chromosome representation of this solution. The numbers inside the boxes are customers' ids and the ones above the boxes indicate the sequence based on which the vehicle visits the customers.

\begin{tabular}{|c|c|c|c|c|c|c|}
\hline 1 & 2 & 3 & 4 & 5 & \multirow[t]{3}{*}{6} & \multirow[t]{3}{*}{7} \\
\hline 2 & 1 & 6 & 5 & \multirow[t]{2}{*}{$Q_{1}$} & & \\
\hline 7 & 4 & $Q_{1}$ & & & & \\
\hline 3 & 8 & 9 & 11 & 12 & 10 & $O_{1}$ \\
\hline 6 & 3 & 7 & $\overline{Q_{2}}$ & & & \\
\hline 8 & 5 & 1 & 2 & $\overline{Q_{2}}$ & & \\
\hline 11 & 9 & 12 & 10 & 4 & $Q_{2}$ & \\
\hline
\end{tabular}

\subsection{Memetic Algorithm}

The steps of memetic algorithm are as follows:

\section{Step 1: Initiation.}

Generate chromosomes randomly.

If the chromosome is a feasible solution,

Collect chromosomes to obtain defined population

\section{Step 2: Evaluation}

Calculate the value of two objective functions.

Calculate the fitness value.

\section{Step 3: Selection}

Select four parents using roulette wheel method of selection from current population.

\section{Step 4: Operators}

Apply crossover operator on selected parents to generate offspring.

Apply mutation operator on selected parents to generate offspring.

Calculate the fitness value. 
Apply TS algorithm for generated offspring.

Calculate the value of two objective functions.

Calculate the fitness value.

Choose the best offspring according to fitness value and remove the other offspring.

Put the current solution (chromosome) into new population.

\section{Step 6: Termination}

If the evolution loops replicate invariable times, stop the run, if not, go to step 3.

It is worthwhile to mention that we use roulette wheel method for generating the parents in step 3. It means that there is randomness in selecting the offspring. In addition, in the local search, we first apply TS algorithm, then we choose the best offspring. Hence, we do not necessarily select super genes or super chromosomes.

\section{Computational results}

In this section, 10 sample problems are developed in order to show the applicability of the model. In developing the sample problems, parameters assumed in PRODHON sample problems are applied. These parameters include location coordinates of the nodes; number of customers; number of potential locations for treatment facilities; demand nodes for waste type 1; maximum capacity of treatment facilities; fixed opening cost of treatment facilities; maximum capacity of vehicles; and cost of using vehicles for transporting hazardous wastes. Other parameters which are shown in Table 3are randomly generated. Table 4 indicates general specifications and size of the test problems.

Table 3. Data used in the test problems.

\begin{tabular}{|cl|}
\hline Parameter & Range (uniform) \\
\hline$H$ & Half capacity of vehicle for HazMat in Prodhon tests \\
$\alpha_{i}$ & {$[0,0.1]$} \\
$B$ & {$[0-0.5]$} \\
$\Lambda$ & {$[0-10]$} \\
$D_{i}$ & {$[10-20][1-10]$} \\
$G_{i}$ & {$[100000-500000]$} \\
$L$ & Double capacity of vehicle for HazMat in Prodhon \\
& tests \\
$O_{i}$ & {$[200-1000]$} \\
$P_{i}$ & {$[50-100]$} \\
$q, r$ & $\{1,2,3\}$ \\
$R_{i j}$ & {$[0-100][0-50][10-30]$} \\
\hline
\end{tabular}


Table 4. Size of the test problems.

\begin{tabular}{|c|c|c|c|c|c|}
\hline $\begin{array}{c}\text { Problem } \\
\text { No. }\end{array}$ & $\begin{array}{c}\text { No. of } \\
\text { Customer }\end{array}$ & $\begin{array}{c}\text { No. of potential } \\
\text { disposal centres }\end{array}$ & $\begin{array}{c}\text { No. of potential } \\
\text { treatment centres }\end{array}$ & $\begin{array}{c}\text { No. of } \\
\text { waste type }\end{array}$ & $\begin{array}{c}\text { Vehicle } \\
\text { capacity }\end{array}$ \\
\hline 1 & 5 & 3 & 3 & 1 & 70 \\
\hline 2 & 10 & 5 & 5 & 2 & 70 \\
\hline 3 & 20 & 5 & 5 & 2 & 70 \\
\hline 4 & 20 & 5 & 5 & 2 & 70 \\
\hline 5 & 20 & 5 & 5 & 2 & 150 \\
\hline 6 & 20 & 5 & 5 & 3 & 70 \\
\hline 7 & 20 & 5 & 5 & 4 & 70 \\
\hline 8 & 50 & 10 & 5 & 2 & 70 \\
\hline 9 & 100 & 10 & 5 & 2 & 70 \\
\hline 10 & 200 & 10 & 20 & 2 & 70 \\
\hline
\end{tabular}

For solving a $n$-objective model, fitness function incorporates the objective functions as follows:

$\operatorname{Max} Z(x)=\sum_{i=1}^{p} \Gamma_{i} Z_{i}(x)$

Subject to:

$x \in F_{d}$

$\Gamma_{i}$, which is a non-negative number, is the corresponding weight of $i^{\text {th }}$ objective function. The weights are chosen based on the priority of objective functions. The new objective function for location and routing bi-objective models is as follows:

$Z_{\text {New }}=\Gamma\left(\frac{Z_{1}}{Z_{1}^{*}}\right)+(1-\Gamma)\left(\frac{Z_{2}}{Z_{2}^{*}}\right)$

Where $Z_{1}$ and $Z_{2}$ are first and second objective functions and $Z^{*}$ denotes the optimal objective value obtained from solving single-objective model.

Due to the significant negative effects of transporting hazardous wastes and people's sensitivity to it, it is supposed that decreasing risk has higher priority than cost. Hence a greater weight is assigned to risk and undesirability. In this study, we assume that weight of the risk and undesirability is 0.6 , and weight of the cost is 0.4 .

Test problems are solved using LINGO version 14.00 on a Dell, LATITUDE D630, Intel(R) Core 2 DUO $2 \mathrm{GHz}$ computer with 2 GB RAM. Besides solving the problems to optimality, they are solved using MA, and the results are shown in Table 5. Figure 6 demonstrates run times of both exact and heuristic methods when cost is the only objective function. Figure 7 shows the run times in case that risk is the only objective function. Figure 8 indicates the run times of those two methods in case that both cost and risk are considered as objective functions. 
Table 5. Computational results.

\begin{tabular}{|c|c|c|c|c|c|c|c|c|c|c|c|c|c|c|c|c|c|}
\hline \multirow{3}{*}{$\begin{array}{l}\text { ż } \\
\frac{0}{0} \\
0 \\
\dot{0} \\
\dot{0} \\
\dot{z}\end{array}$} & \multirow{3}{*}{ Objective function } & \multicolumn{8}{|c|}{ Location Problem (Bi-Objective model with $\mathrm{Z1}$ and $\mathrm{Z} 2$ as objective functions) } & \multicolumn{8}{|c|}{$\begin{array}{c}\text { Routing Problem (Bi-Objective model with } \mathrm{Z3} \text { and } \mathrm{Z4} \text { as } \\
\text { objective functions) }\end{array}$} \\
\hline & & \multicolumn{3}{|c|}{ LINGO } & \multicolumn{3}{|c|}{ MA } & \multicolumn{2}{|c|}{ Error $(\%)$} & \multicolumn{3}{|c|}{ LINGO } & \multicolumn{3}{|c|}{ MA } & \multicolumn{2}{|c|}{ Error $(\%)$} \\
\hline & & $\mathbf{Z}_{1}$ & $\mathbf{Z}_{2}$ & Time & $\mathbf{Z}_{1}$ & $\mathbf{Z}_{2}$ & Time & $\mathrm{Z}_{1}$ & $\mathbf{Z}_{2}$ & $\mathbf{Z}_{3}$ & $\mathbf{Z}_{\mathbf{4}}$ & time & $\mathbf{Z}_{3}$ & $\mathbf{Z}_{4}$ & time & $Z_{3}$ & $\mathbf{Z}_{4}$ \\
\hline \multirow{3}{*}{1} & First objective function & $1.41 \mathrm{E}+07$ & 287263 & $\overline{0}$ & $1.41 \mathrm{E}+07$ & 287263 & $\overline{0}$ & 0 & 0 & 5051 & 90 & 300 & 5053 & 90 & 174 & 0.03 & 0 \\
\hline & Second objective function & $2.82 \mathrm{E}+07$ & 231516 & 0 & $2.82 \mathrm{E}+07$ & 231516 & 0 & 0 & 0 & 5219 & 66 & 350 & 5217 & 66 & 4 & 0.03 & 0 \\
\hline & Both objective & $1.48 \mathrm{E}+07$ & 251328 & 0 & $1.48 \mathrm{E}+07$ & 251328 & 0 & 0 & 0 & 5079 & 94 & 279 & 5081 & 94 & 1 & 0.03 & 0 \\
\hline \multirow{3}{*}{2} & First objective function & $4.54 \mathrm{E}+08$ & 333863 & 0 & $4.54 \mathrm{E}+08$ & 333863 & 0 & 0 & 0 & & & & 10317 & 752 & 426 & & \\
\hline & Second objective function & $4.45 \mathrm{E}+08$ & 345199 & 8 & $4.45 \mathrm{E}+08$ & 345199 & 0 & 0 & 0 & & & & 11215 & 121 & 116 & & \\
\hline & Both objective & $4.45 \mathrm{E}+08$ & 345100 & 3 & $4.45 \mathrm{E}+08$ & 345100 & 0 & 0 & 0 & & & & 10845 & 211 & 80 & & \\
\hline \multirow{3}{*}{3} & First objective function & $3.51 \mathrm{E}+10$ & 321768 & 0 & $3.51 \mathrm{E}+10$ & 321768 & 0 & 0 & 0 & & & & 16625 & 1974 & 129 & & \\
\hline & Second objective function & $3.42 \mathrm{E}+10$ & 427215 & 6 & $3.42 \mathrm{E}+10$ & 427215 & 0 & 0 & 0 & & & & 20418 & 135 & \begin{tabular}{|l|}
2135.64 \\
\end{tabular} & & \\
\hline & Both objective & $3.51 \mathrm{E}+10$ & 321778 & 2 & $3.51 \mathrm{E}+10$ & 321778 & $\overline{0}$ & 0 & 0 & & & & 17477 & 259 & 110.646 & & \\
\hline \multirow{3}{*}{4} & First objective function & $1.37 \mathrm{E}+10$ & 125519 & 1 & $1.37 \mathrm{E}+10$ & 125519 & 0 & 0 & 0 & & & & 16572 & 1762 & 972 & & \\
\hline & Second objective function & $5.37 \mathrm{E}+09$ & 148298 & 5 & $5.37 \mathrm{E}+09$ & 148298 & 0 & 0 & 0 & & & & 20106 & 152 & 988 & & \\
\hline & Both objective & $5.48 \mathrm{E}+09$ & 140874 & 2 & $5.48 \mathrm{E}+09$ & 140874 & 1 & 0 & 0 & & & & 17646 & 365 & 24 & & \\
\hline \multirow{3}{*}{5} & First objective function & $1.37 \mathrm{E}+10$ & 125519 & 1 & $1.37 \mathrm{E}+10$ & 125519 & 0 & 0 & 0 & & & & 8558 & 1421 & 973 & & \\
\hline & Second objective function & $5.37 \mathrm{E}+09$ & 148298 & 5 & $5.37 \mathrm{E}+09$ & 148298 & 0 & 0 & 0 & & & & 12365 & 144 & 988 & & \\
\hline & Both objective & $5.48 \mathrm{E}+09$ & 140874 & 2 & $5.48 \mathrm{E}+09$ & 140874 & 1 & 0 & 0 & & & & 9627 & 318 & 38 & & \\
\hline \multirow{3}{*}{6} & First objective function & $1.09 \mathrm{E}+10$ & 213762 & 1 & $1.09 \mathrm{E}+10$ & 213762 & 1 & 0 & 0 & & & & 27893 & 4160 & 1484 & & \\
\hline & Second objective function & $9.12 \mathrm{E}+09$ & 231641 & 8 & $9.12 \mathrm{E}+09$ & 231641 & 1 & 0 & 0 & & & & 32676 & 346 & 1585 & & \\
\hline & Both objective & $9.23 \mathrm{E}+09$ & 224217 & 5 & $9.23 \mathrm{E}+09$ & 224217 & 2 & 0 & 0 & & & & 29248 & 905 & 241 & & \\
\hline \multirow{3}{*}{7} & First objective function & $3.86 \mathrm{E}+10$ & 234837 & 1 & $3.86 \mathrm{E}+10$ & 234837 & 2 & 0 & 0 & & & & 33294 & 5078 & 2040 & & \\
\hline & Second objective function & $1.78 \mathrm{E}+10$ & 259022 & 11 & $1.78 \mathrm{E}+10$ & 259022 & 2 & 0 & 0 & & & & 39245 & 663 & 2117 & & \\
\hline & Both objective & $1.78 \mathrm{E}+10$ & 249022 & 2 & $1.78 \mathrm{E}+10$ & 249022 & 2 & 0 & 0 & & & & 37086 & 1202 & 1759 & & \\
\hline \multirow{3}{*}{8} & First objective function & $1.89 \mathrm{E}+10$ & 331154 & 3 & $1.89 \mathrm{E}+10$ & 331154 & 0 & 0 & 0 & & & & 35876 & 7577 & 1708 & & \\
\hline & Second objective function & $1.06 \mathrm{E}+10$ & 477625 & 255 & $1.06 \mathrm{E}+10$ & 477625 & 0 & 0 & 0 & & & & 57542 & 360 & 2192 & & \\
\hline & Both objective & $1.13 \mathrm{E}+10$ & 391038 & 13 & $1.13 \mathrm{E}+10$ & 391038 & 0 & 0 & 0 & & & & 42909 & 1443 & 807 & & \\
\hline \multirow{3}{*}{9} & First objective function & $6.45 \mathrm{E}+09$ & 290714 & 0 & $6.45 \mathrm{E}+09$ & 291714 & 0 & 0 & 0 & & & & 67657 & 16806 & 220 & & \\
\hline & Second objective function & $2.26 \mathrm{E}+09$ & 464323 & 855 & $2.26 \mathrm{E}+09$ & 464323 & 1 & 0 & 0 & & & & 76943 & 5643 & 3 & & \\
\hline & Both objective & $2.32 \mathrm{E}+09$ & 429052 & 136 & $2.32 \mathrm{E}+09$ & 429152 & 1 & 0 & 0 & & & & 7266 & 72497 & 264 & & \\
\hline \multirow{3}{*}{10} & First objective function & & & & $6.79 \mathrm{E}+05$ & $6.59 \mathrm{E}+16$ & 1 & & & & & & 132836 & 15057 & 194 & & \\
\hline & Second objective function & & & & $2.94 \mathrm{E}+16$ & $1.02 \mathrm{E}+06$ & 1 & & & & & & 246382 & 697 & 52898 & & \\
\hline & Both objective & & & & $3.49 \mathrm{E}+16$ & $7.61 \mathrm{E}+05$ & 1 & & & & & & 140245 & 11453 & 195 & & \\
\hline
\end{tabular}






Figure 6. Run times of exact and heuristic methods in case that cost is the only objective function.

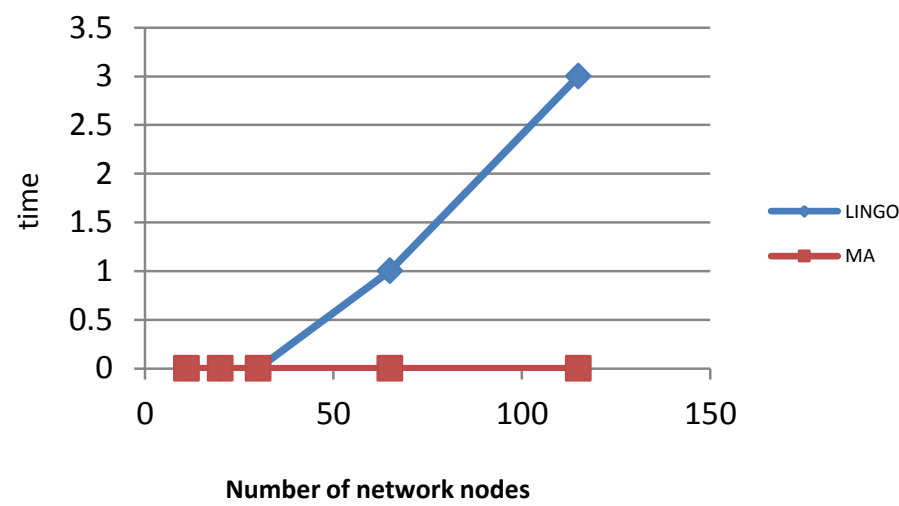

Figure 7. Run times of exact and heuristic methods in case that risk is the only objective function.

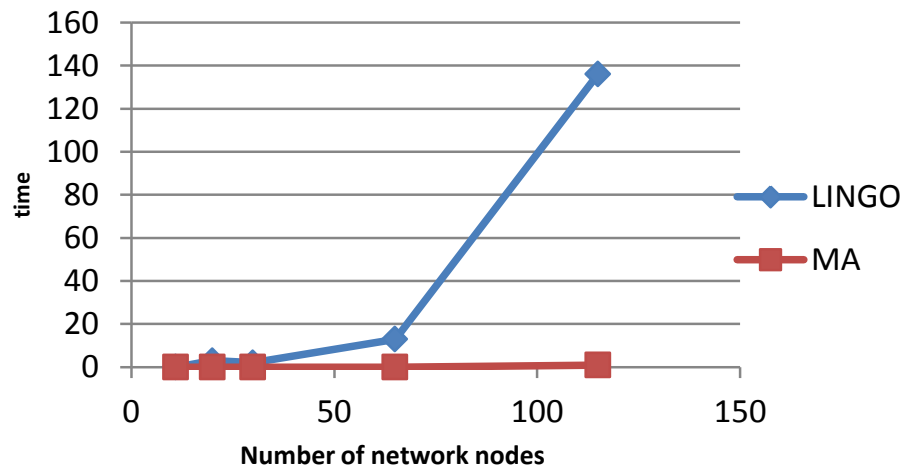

Figure 8. Run times of exact and heuristic methods in case that both cost and risk are objective functions.

\section{Case Study}

In this section we describe structure of HazMat management system in Singapore. Handling HazMat shipments in Singapore, which includes transportation planning, routing and scheduling in order to reduce threat to life and property in the event of fire or explosion, is in the charge of the Singapore Civil Defence Force (SCDF). SCDF has specified approved transport routes in detail. Figure 9 illustrates a general overview of feasible routes for HazMat in Singapore. 


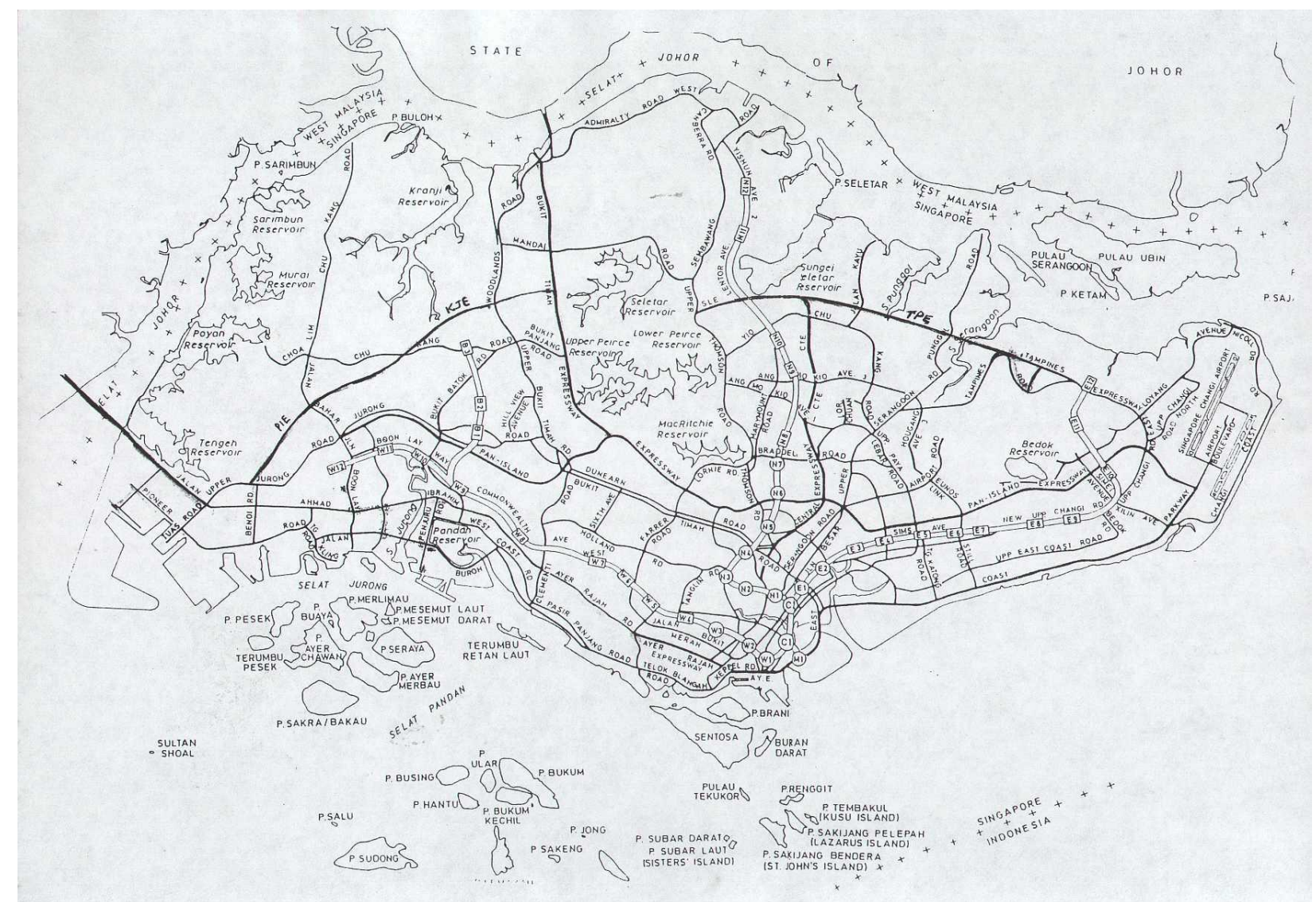

Figure 9. Singapore map approved for HazMat bulk transportation (http://www.scdf.gov.sg).

\subsection{The Transportation Network}

We have considered Meng et al. (2005) network in Singapore. Meng et al. (2005) consider three types of roads including express way, primary and secondary road. Since their data are out-dated we have checked these roads. Several roads have been changed and promoted. However, since we are testing a problem in which types of roads are not playing a key role; we have not focused on it.



Figure 10. HazMat transportation network in Singapore. 


\subsection{Population and Garbage Generation}

Singapore is divided into 28 separate districts. In this case study, we have considered 22 more important districts with respect to population, area and all information we have. Singaporeans live in three kinds of homes: Land, HDB and condominium. At least $80 \%$ of Singaporeans live in HDBs and we know that more than $91 \%$ of them are owner (this means in this part we will have more stable and reliable data that will not change too much in near future); on the other hand we have very precise information about HDBs. (visited in 02.07.2012: http://www.hdb.gov.sg/fi10/fi10221p.nsf/Attachment/UN_Public_Service_Award_2008/\$file/Hom e+Ownership+Programme.html). Thus we can focus on HDBs and justify our predictions with adding $20 \%$ to this kind of data.

In Table 6, the basic data we are using are shown. National statistical authority is responsible for disseminating official statistics on Singapore. Singapore has more than 4.8 million habitant and $63.2 \%$ of them are working. We have assumed that $40 \%$ of these working people leave their districts to the other districts to reach their working place (http://www.singstat.gov.sg/). This information is useful for the first period when all people are staying at home before going to their work place.

Table 6. Calculated populations in different districts of Singapore based on the types of homes they are living in.

\begin{tabular}{|l|c|c|c|c|c|c|}
\hline \multicolumn{1}{|c|}{ District } & Longitude & Latitude & $\begin{array}{c}\text { Total area } \\
\text { (Hectares) }\end{array}$ & Population & $\begin{array}{c}\text { \# of employee } \\
\text { population }\end{array}$ & $\begin{array}{c}\text { \# of employee } \\
\text { leaving district }\end{array}$ \\
\hline Ang Mo Kio & 1.37173 & 103.847641 & 638 & 233255 & 147417 & 58967 \\
\hline Bedok & 1.324658 & 103.932381 & 937 & 311260 & 196716 & 78686 \\
\hline Bishan & 1.350397 & 103.848755 & 690 & 113771 & 71903 & 28761 \\
\hline Bukit Batok & 1.35002 & 103.749268 & 802 & 174970 & 110581 & 44232 \\
\hline Bukit Merah & 1.282653 & 103.818726 & 858 & 243007 & 153580 & 61432 \\
\hline Bukit Panjang & 1.380058 & 103.76432 & 489 & 178773 & 112985 & 45194 \\
\hline CBD & 1.285723 & 103.843801 & - & 43962.5 & 27784 & 11113 \\
\hline Choa Chu Kang & 1.385104 & 103.74501 & 583 & 240838 & 152209 & 60883 \\
\hline Clementi & 1.314352 & 103.765236 & 408 & 119835 & 75735.72 & 30294 \\
\hline Geylang & 1.320613 & 103.886932 & 678 & 149670 & 94591 & 37836 \\
\hline Hougang & 1.372581 & 103.893654 & 1276 & 274824 & 173689 & 69475 \\
\hline Jurong East & 1.324076 & 103.739896 & 384 & 125525 & 79332 & 31732 \\
\hline Jurong West & 1.339681 & 103.706795 & 987 & 401753 & 253908 & 101563 \\
\hline Kallang & 1.300682 & 103.874405 & 799 & 160639 & 101524 & 40609 \\
\hline Pasir Ris & 1.372442 & 103.949547 & 601 & 175276 & 110775 & 44309 \\
\hline Punggol & 1.398487 & 103.907924 & 957 & 109165 & 68992 & 27596 \\
\hline Queenstown & 1.29883 & 103.804001 & 667 & 138506 & 87536 & 35014 \\
\hline Sembawang & 1.448197 & 103.819485 & 708 & 112392 & 71032 & 28412 \\
\hline Sengkang & 1.389308 & 103.899536 & 1055 & 268668 & 169798 & 67919 \\
\hline Serangoon & 1.353446 & 103.872384 & 737 & 121648 & 76882 & 30752 \\
\hline Tampines & 1.352481 & 103.944611 & 1200 & 355551 & 224708 & 89883 \\
\hline Toa Payoh & 1.331461 & 103.849503 & 463 & 177833 & 112390 & 44956 \\
\hline Woodlands & 1.436046 & 103.786057 & 1198 & 346486 & 218979 & 87591 \\
\hline Yishun & 1.429725 & 103.835907 & 810 & 257313 & 162622 & 65048 \\
\hline
\end{tabular}




\subsection{Hazardous Waste Types}

For HazMat shipments usually a 3-PL company has to apply for SCDF and ask for permission about the time and the route of shipment. SCDF will investigate the application with respect to the shipment specifications including HazMat class type, amount of it and also requested time span and will make the final decision.

SCDF has divided the approved HazMat class types into two main groups as follows:

- Petroleum (including Class 0,1,2 and three with respect to flash point)

- Flammable Materials (Flammable Materials listed in the Second Schedule of the Fire Safety (Petroleum and Flammable Materials) Regulations 2005. These are numbered 237 types.

The common licensable products which for them license application are needed can be found in SCDF website:

(http://www.scdf.gov.sg/Building_Professionals/Fire_Safety_Licensing_and_Enforcement/Petroleu $\underline{\text { m_Storage_Tpt.html) }}$

\subsection{HazMat Risks}

In this case study we have considered the two major groups as the HazMat class types. Therefore, we have two HazMat types: petroleum and flammable materials. For the first group (petroleum) we have considered the worst case (the lowest flash point). Therefore, we set its evacuation distance equal to 1600 meters (Verter and Kara, 2008). For the second group (flammable materials) the impact zone is 800 meters in all directions (Meng et al., 2005); i.e. total population exposed for the class-1 HazMat is four time bigger than that for class-2 HazMat.

\subsection{Results and insights}

In order to solve a real world problem, we use data of the Singapore case study, and adjust them to fit the model. To solve the problem, 3 nodes are added to the network as potential locations for treatment centers. In addition, 2 nodes of the network are considered as potential locations for disposal centers. Based on the results, the disposal center, and treatment centers $Q_{1}$ and $Q_{2}$ are established in nodes 22,25 , and 24 , respectively.

According to the results, undesirability of the network grows significantly by increasing types of wastes, particularly when considering cost as the only objective function. However, it does not have a major effect on treatment and disposal facilities location costs. Similarly, transportation costs and vehicles leasing or purchasing costs do not change significantly. Moreover, changing number of customers results in a huge boost in undesirability. We infer from the results that both cost and risk increase as predicted, but the increasing rate of undesirability is much more than that of cost and risk. It is worth mentioning that the increase in risk is more than cost. 
In order to investigate the impact of vehicle capacity on results, it is doubled while other parameters are constant. We observe that transportation costs decrease by half while risk diminishes by a small amount, however, undesirability and other costs do not change. It can be deduced that changing the capacity of fleet or vehicles is an operational strategy throughout the network.

\section{Conclusions and Future Research}

We proposed a three-objective model for hazardous waste location-routing problem. The proposed model is decomposed into two models and solved separately; location problem and routing problem. The results of the location model are considered as parameters in the routing model. The developed formulation in this paper makes the LRP capable of being solved for location and routing problems separately. Accordingly, it is solvable for any risk and cost measures of location and routing problems independently.

Most problems solved in the literature are small-sized. The largest problem ever solved is the one considered by Alumur and Kara (2007), with 92 generation nodes and 20 candidate sites. In this paper, a large-scale problem is solved containing 200 generation nodes and 30 candidate sites whereas the computational time was less than that of Alumur and Kara (2007).

Some wastes such as hospital and civil wastes cannot be transported together, and they also need different treatment technologies. Accordingly, various types of wastes and several treatment technologies have been considered in this research, which is more realistic. Based on this, wastes are sent to treatment facilities with relevant technologies.

Literature review reveals the lack of an effective meta-heuristic method to solve LRP problems. This paper presents a meta-heuristic method which is effective in terms of computational time and quality of the solution. A memetic algorithm is designed alongside a TS algorithm that does the local search. The performance of the proposed meta-heuristic method is compared with that of the exact method.

One assumption in this paper is that all parameters in the problem are deterministic and there is no uncertainty in the problem while, in practice, parameters like costs, undesirability factor, and the population of the region are mostly probabilistic or even fuzzy. Using different methods such as iterative or nested method, other heuristic and meta-heuristic methods like SA, AC, and comparing the quality of solutions and computational times would be a significant contribution.

It should be noted that inventory management has not yet attracted much attention in LRP problems. In this case, in addition to finding optimum locations and tours, facility inventory constraints must be considered in the model. Furthermore, using step functions for transportation costs as a function of transport weight (Ghiani et al., 2004) makes the problem more realistic. Prices 
offered by transporters are often nonlinear and, sometimes, step function. Using this type of cost structure may constitute further development for this research.

\section{REFERENCES}

Aksen D, Altinkemer K. A location-routing problem for the conversion to the click-and-mortar retailing: The static case. European Journal of Operational Research 2008; 186(2): 554-575.

Alumur S, Kara BY. A new model for the hazardous waste location-routing problem. Computers and Operations Research 2007; 34(5): 1406-1423.

Ambrosino D, Scutella MG. Distribution network design: New problems and related models. European Journal of Operational Research 2005; 165(3): 610-624.

Androutsopoulos KN, Zografos KG. Solving the bicriterion routing and scheduling problem for hazardous materials distribution. Transportation Research Part C: Emerging Technologies 2010; 18(5): 713-726.

Androutsopoulos KN, Zografos KG. A bi-objective time-dependent vehicle routing and scheduling problem for hazardous materials distribution. EURO Journal on Transportation and Logistics 2012; 1(1-2): 157-183.

Assadipour G, Ke GY, Verma M. Planning and managing intermodal transportation of hazardous materials with capacity selection and congestion. Transportation Research Part E 2015; 76: 4557.

Balakrishnan A, Ward JE, Wong RT. Integrated facility location and vehicle routing models: Recent work and future prospects. American Journal of Mathematical Sciences 1987; 7(1-2): 35-61.

Baldacci R., Mingozzi A, Calvo RW. An exact method for the capacitated location-routing problem. Operations Research 2011; 59(5): 1284-1296.

Barreto S, Ferreira C, Paixao J, Santos BS. Using clustering analysis in a capacitated locationrouting problem. European Journal of Operational Research 2007; 179(3): 968-977.

Belenguer JM, Benavent E, Prins C, Prodhon C, Calvo RW. A branch-and-cut method for the capacitated location-routing problem. Computers and Operations Research 2011; 38(6): 931941.

Bronfman A, Marianov V, Paredes-Belmar G, Lüer-Villagra A. The maximin HAZMAT routing problem. European Journal of Operational Research 2015; 241 (1): 15-27.

Boudia M, Prins C. A memetic algorithm with dynamic population management for an integrated production-distribution problem. European Journal of Operational Research 2009; 195(3): 703715.

Boyer O, Hong TS, Pedram A, Yusuff RBM, Zulkifli N. A mathematical model for the industrial hazardous waste location-routing problem. Journal of Applied Mathematics 2013; 2013: 1-10.

Berglund PG, Kwon C. Robust facility location problem for hazardous waste transportation. Networks and Spatial Economics 2014; 14(1): 91-116.

Caballero R, Gonzalez M, Guerrero FM, Molina J, Paralera C. Solving a multiobjective location routing problem with a metaheuristic based on tabu search: Application to a real case in Andalusia. European Journal of Operational Research 2007; 177(3): 1751-1763.

Cappanera P, Gallo G, Maffioli F. Discrete facility location and routing of obnoxious activities. Discrete Applied Mathematics; 2003; 133(1-3): 3-28.

Chan Y, Baker SF. The multiple depot, multiple traveling salesmen facility-location problem: Vehicle range, service frequency and heuristic implementations. Mathematical and Computer Modelling 2005; 41(8-9): 1035-1053. 
Chan Y, Carter WB, Burnes MD. A multiple-depot, multiple-vehicle, location-routing problem with stochastically processed demands. Computers and Operations Research 2001; 28(8): 803-826.

Current J, Ratick S. A model to assess risk, equity and efficiency in facility location and transportation of hazardous materials. Location Science 1995; 3(3): 187-201.

Dalfard VM, Kaveh M, Nosratian NE. Two meta-heuristic algorithms for two-echelon locationrouting problem with vehicle fleet capacity and maximum route length constraints. Neural Computing and Applications 2013; 23(7-8): 2341-2349.

Derbel H, Jarboui B, Hanafi S, Chabchoub H. Genetic algorithm with iterated local search for solving a location-routing problem. Expert Systems with Applications 2012; 39(3): 2865-2871.

Derigs U, Li B, Vogel U. Local search-based metaheuristics for the split delivery vehicle routing problem. The Journal of the Operational Research Society 2010; 61(9): 1356-1364.

Doerner K, Focke A, Gutjahr WJ. Multicriteria tour planning for mobile healthcare facilities in a developing country. European Journal of Operational Research 2007; 179(3): 1078-1096.

Duhamel C, Lacomme P, Prins C, Prodhon C. A GRASP $\times$ ELS approach for the capacitated location-routing problem. Computers and Operations Research 2010; 37(11): 1912-1923.

Escobar JW, Linfati R, Toth P. A two-phase hybrid heuristic algorithm for the capacitated locationrouting problem. Computers and Operations Research 2013; 40(1): 70-79.

Ghiani G, Laporte G, Musmanno R. Introduction to logistics systems planning and control. John Wiley and Sons, West Sussex 2004.

Giannikos I. A multi-objective programming model for locating treatment sites and routing hazardous wastes. European Journal of Operational Research 1998; 104(2): 333-342.

Jacobs TL, Warmerdam JM. Simultaneous routing and siting for hazardous-waste operations. Journal of Urban Planning and Development 1994; 120(3): 115-131.

Karaoglan I, Altiparmak F, Kara I, Dengiz B. The location-routing problem with simultaneous pickup and delivery: Formulations and a heuristic approach. Omega 2012; 40(4): 465-477.

Li L, Wang S, Lin Y, Liu W, Chi T. A covering model application on Chinese industrial hazardous waste management based on integer program method. Ecological Indicators 2015; 51: 237-243.

Li R, Leung Y. Multi-objective route planning for dangerous goods using compromise programming. Journal of Geographical Systems 2011; 13(3): 249-271.

List G, Mirchandani P, Turnquist MA, Zografos KG. An integrated network/planar multiobjective model for routing and siting for hazardous materials and wastes. Transportation Science 1991; 25(2): 146-156.

McKinnon A, Cullinane S, Browne M, Whiteing A. Green Logistics: Improving the environmental sustainability of Logistics. Kogan Page 2010.

Meng Q, Lee DH, Cheu RL. Multiobjective vehicle routing and scheduling problem with time window constraints in hazardous material transportation. ASCE Journal of Transportation Engineering 2005; 131(9): 699-707.

Moccia L, Cordeau JF, Laporte G. An incremental tabu search heuristic for the generalized vehicle routing problem with time windows. The Journal of the Operational Research Society 2012; 63(2): 232-244.

Min H, Jayaraman V, Srivastava R. Combined Location-Routing problems: A synthesis and future research directions. European Journal of Operational Research 1998; 108(1): 1-15.

Moghaddam RT, Safaei N, Sassani F. A memetic algorithm for the flexible flow line scheduling problem with processor blocking. Computers and Operations Research 2009; 36(2): 402-414.

Nema AK, Gupta SK. Optimization of regional hazardous waste management systems: An improved formulation. Waste Management 1999; 19(7-8): 441-451. 
Nema AK, Gupta SK. Multiobjective risk analysis and optimization of regional hazardous waste management system. Practice Periodical of Hazardous, Toxic, and Radioactive Waste Management 2003; 7(2): 69-77.

Nguyen VP, Prins C, Prodhon C. Solving the two-echelon location routing problem by a GRASP reinforced by a learning process and path relinking. European Journal of Operational Research 2012a; 216(1): 113-126.

Nguyen VP, Prins C, Prodhon C. A multi-start iterated local search with tabu list and path relinking for the two-echelon location-routing problem. Engineering Applications of Artificial Intelligence 2012b; 25(1): 56-71.

Pishvaee M, Farahani RZ, Dullaert W. A memetic algorithm for bi-objective integrated forward/reverse logistics network design. Journal of Computer and Operation Research 2009; 37(1): 1100-1112.

Pradhananga R, Taniguchi E, Yamada T. Ant colony system based routing and scheduling for hazardous material transportation. Procedia - Social and Behavioral Sciences 2010; 2(3): 60976108

Prodhon C. (2008), <http://losi.utt.fr/fr/membres/prodhonc.html $>$

Revelle C, Cohon J, Shobrys D. Simultaneous siting and routing in the disposal of hazardous wastes. Transportation Science 1991; 25(2): 138-145.

Samanlioglu F. A multi-objective mathematical model for the industrial hazardous waste locationrouting problem. European Journal of Operational Research 2013; 226(2): 332-340.

Sambola MA, Diaz JA, Fernandez E. A compact model and tight bounds for a combined locationrouting problem. Computers and Operations Research 2005; 32(3): 407-428.

Sambola MA, Fernandez E, Laporte G. Heuristic and lower bound for a stochastic location-routing problem. European Journal of Operational Research 2007; 179(3): 940-955.

Shen Z, Hassani A, Shi Q. Multi-objective time-cost optimization using Cobb-Douglas production function and hybrid genetic algorithm. Journal of Civil Engineering and Management 2015; 1-2.

Stowers CL, Palekar US. Location models with routing considerations for a single obnoxious facility. Transportation Science 1993; 27(4): 350-362.

Ting CJ, Chen $\mathrm{CH}$. A multiple ant colony optimization algorithm for the capacitated location routing problem. International Journal of Production Economics 2013; 141(1): 34-44.

Tuzun D, Burke LI. A two-phase tabu search approach to the location routing problem. European Journal of Operational Research 1999; 116(1): 87-99.

Verter V, Kara BY. A path-based approach for hazmat transport network design. Management Science 2008; 54(1): 29-40.

Wasner M, Zapfel G. An integrated multi-depot hub-location vehicle routing model for network planning of parcel service. International Journal of Production Economics 2004; 90(3): 403-419.

Wu TH, Low C, Bai JW. Heuristic solutions to multi-depot location-routing problems. Computers and Operations Research 2002; 29(10): 1393-1415.

Wyman MM, Kuby M. Proactive optimization of toxic waste transportation, location and technology. Loculion Science 1995; 3(3): 167-185.

Xie Y, Lu W, Wang W, Quadrifoglio L. A multimodal location and routing model for hazardous materials transportation. Journal of Hazardous Materials 2012; 227-228: 135-141.

Yu VF, Lin SW, Lee W, Ting CJ. A simulated annealing heuristic for the capacitated location routing problem. Computers and Industrial Engineering 2010; 58(2): 288-299. 
Zhang M, Ma Y, Weng K. Location-routing model of hazardous materials distribution system based on risk bottleneck. Proceedings of International Conference on Services Systems and Services Management (ICSSSM) 2005; 1: 362-368.

Zhao J, Verter V. A bi-objective model for the used oil location-routing problem. Computer \& Operation Research 2015; 62: 157-168.

Zografos KG, Samara S. Combined location-routing model for hazardous waste transportation and disposal. Transportation Research Record 1989; 1245: 52-59. 